\title{
Geometrical Model of Fixed Parts and Movable Parts Projected Shaft Star of SIRM by GA and Conventional Method to Minimize the Pulling Force Fluctuation
}

\author{
P.Rajasekaran, K.Boopathy, K.Jayaseelan, A.Santhosh, P.Akhilan, Mohammed Siajid Akaram \\ Abbigeri
}

\begin{abstract}
In this article, focus on modeling of switched reluctance motor (SiRM) The flux assets of the iron, the number of phases, and the number of projected portion per phase all have a irregular properties on this Devices. These possessions, along with the sizing of the Device cover and internal scopes, kind the Device project an insight-intensive struggle. Enlargement of pulling force density, power output, and lowering location of pulling force fluctuation, heat escalation, audio sound. A design organization that exploits the desired features and reduces the undesirable effects is obtainable here. Static and dynamic system-level simulations and finite-element analysis have been accepted out for a 3-phase 6/4 2.4-kW SIRM, at various rated electrons flow assessment for both conventional design and genetic procedure design methods and the results were verified using standard reproductions. The result seems to be stirring. The results demonstrate suitable projected shaft star Curve and movable parts Curve of a pulling force -fluctuation minimized SiRM drive.
\end{abstract}

Keywords - Evaluation Programme, SiRM (Switched Reluctance Motor), Pulling force Lowering location, Shape Optimization. Pulling force fluctuation, pulling force dip.

\section{Nomenclature}

I Phase electrons flow, in amperes.

$\theta_{\mathrm{x}} \quad$ Movable parts location, in degrees.

$\mathrm{N}_{\mathrm{r}}$ Movable parts speed, in revolutions per minute.

$\Psi \quad$ Flux linkage, in Weber-turns.

L Non linear phase $\mathrm{L}$ value, in henries.

$\mathrm{B}_{\mathrm{s}} \quad$ Flux thickness at maximal Flux wastage

$\lambda$ matching /unmatching $\mathrm{L}$ value ratio

q Total number of phases

g air gap

$\mathrm{r}_{1} \mathrm{R}$ dia

$\beta r R$ projected shaft star Curve

$\beta$ s $S$ projected shaft star Curve $\mathrm{T} / \mathrm{v} \quad$ Instantaneous developed pulling force, in Newton meters.

Revised Manuscript Received on December 11, 2019

P.Rajasekaran*, Associate Professor, Department of EEE, Aarupadai Veedu Institute of Technology, Chennai, India.

Dr.K.Boopathy, Professor, Department of EEE, Aarupadai Veedu Institute of Technology, Chennai, India. E-mail: boopathyk@avit.ac.in.org

K.Jayaseelan, A.santhosh, P.Akhilan, Mohammed Siajid Akaram Abbigeri, UG Students, Department of EEE , Aarupadai Veedu Institute of Technology, Chennai, India.

\section{INTRODUCTION}

The switched reluctance Device (SiRM) $[1,2]$ is a viable participant for a number of submissions that require high dependability, constant energy for variable parts, low developed price, and fast dynamic response. Like all other Devices, the SiRM has a exclusive set of features that make it suitable for certain applications and inappropriate for others. The specific allowance of the numerous design objectives is mutual to all solicitations. The final nonexistence of windings, brushes or permanent magnets in the movable parts is one of the most outstanding features of the SiRM, due to which it has an advantage of high pulling force to weight ratio.[3,4] This feature makes the movable parts mechanically and thermally very robust. The control requirements for the SIRM are deceptively complicated, especially when used for servo-type applications. The design of the SR Device becomes complicated due to the complex shape of shaft of the motor. The primary disadvantages of SIRMs are the pulling force fluctuation and acoustic noise.

During the past periods, rese Curve had been done to condense the pulling force fluctuation and audio noise. Several control methods, motor designs, and power equipment's reverse network configuration had been future which now make the SiRM motor a likely candidate for many drive applications, such as servo drives and traction drives of hybrid electric vehicles. [4]

This paper investigates the reducing of the pulling force fluctuation by making geometrical changes in the SIRM. A unwillingness Device is one in which the pulling force is produced by the tendency of its movable portion to move to a location, where $\mathrm{L}$ value of the excited winding is maximized and the unwillingness is minimum. Such a pulling force is called reluctance pulling force. It has wound field coils for its fixed parts windings and has no coils or magnets on its movable parts. Both the fixed parts and movable parts have noticeable projected portion, hence the Device is devoted to as a doubly salient motor. The fixed parts: movable parts projected portion can be $2 ; 4,4 ; 8,4^{\prime} 6,10: 8,6: 10$ etc [5].

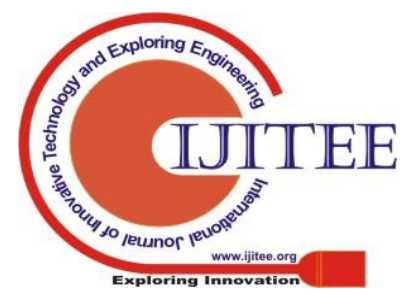


The windings in the diametrically opposite fixed parts projected portion form 'one phase' of the SIRM. So, if there are 8 fixed parts windings (projected portion), then it will become a ' 4 phase' SIRM. The movable part is matching whenever diametrically opposite fixed parts projected portion are excited. While two movable parts projected another set of projected portion is out of alignment with respect to a different set of fixed parts projected portion. Then, this set of fixed parts projected portion is excited to bring the movable parts projected portion into alignment. Likewise, by sequentially switching the electrons flows into the fixed parts windings, the movable parts is rotated. Fig. 1 shows 3-D view of conventional model of SIRM.

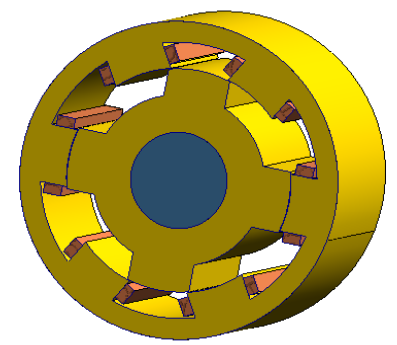

Fig. 1. 3D View of conventional SIRM

\section{MODELING OF SIRM USING FEM}

Dimensions of a $6 / 4$ projected shaft star SIRM drawn are

- Fixed parts outer radius: $76 \mathrm{~mm}$

- Fixed parts inner radius: $66 \mathrm{~mm}$

- Movable parts outer radius: $41 \mathrm{~mm}$

- Movable parts inner radius: $23 \mathrm{~mm}$

- Fixed parts projected shaft star Curve : 32 o

- Movable parts projected shaft star Curve : 29o

- Air-gap length : $0.25 \mathrm{~mm}$

The Device is then solved using the finite element method using MagNet 6.0. The solving procedure of SIRM involves three processes- pre-processing, meshing, post-processing. Fig .2 shows the standard model of SIRM [6]

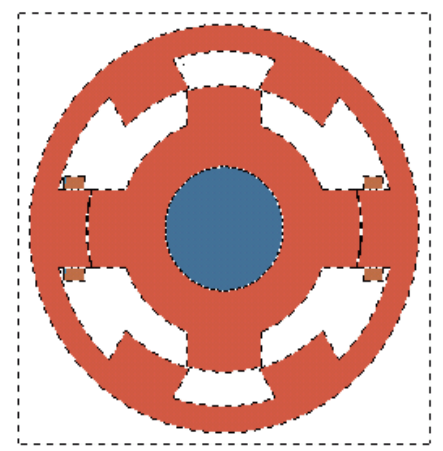

Fig. 2. Standard 3phase SIRM model

\section{REVIEW OF PREVIOUS METHODS}

SIRM consists of two distinguished difficulties, (i.e) more pulling force fluctuation in the advanced pulling force and vibration. From previous both spans figure of fresh methods portion are matching to the two fixed parts projected portion,

had been reported, addressing to recover the pulling force profile and reduce pulsation [1, 4, and 5]

The main articles have been circulated in the literature [5] lecturing the strategy and shape modifications for the improvements in pulling force profile. Device designers had tried to maximize the pulling force output developed in SIRM by changing the projected shaft star Curve to projected shaft star pitch ratio of fixed parts and movable parts projected portion. Various modifications on movable parts shape of shaft, such as surface profiling of the movable parts projected shaft star face and twisting and shape changing of the movable parts projected portion has been noted [5]. While related to the parallel-sided projected shaft star arrangement, chamfering of the movable parts projected portion was observed not to offer much development in pulling force. In projected parts portion it was no variations measured in skewing movable parts. As reported in [4], modifications in the movable parts projected shaft star Curve concluded in alternate in the average pulling force. Besides the above mentioned movable parts shape of shaft modifications in the fixed parts projected shaft star shape of shaft was analyzed with multiple-tooth. The shape of shaft that produced the highest average pulling force has selected for modelling.

SIRM's have an excessive benefit of load pulling force to weight deviation. Any escalation in the size of movable parts for a better load pulling force profile will certainly affect this feature. Also, as the movable parts projected shaft star Curve to projected shaft star pitch ratio in SIRM has to be between 0.295 and 0.415 [2-3].

The work done by [2] is based on fixed parts projected shaft star shaping, where in the pulling force fluctuation is minimized by widening the fixed parts projected shaft star Curve by affixing fixed parts projected shaft star shoes. In [5] presents an improved PWM electrons flow control technique for pulling force fluctuation lowering location in the low speed mode of operation. The drawback of this method is that projected shaft star design is not concentrated and also optimization tool is not applied to maximize electrons flow. Work by Husain [5] shows that a good dynamic response could be achieved by replacing a closed loop electrons flow controller with a flux-linkage controller. Although the fluxlinkage controller gives a deadbeat response, it does require knowledge of the Device characteristics and accurate movable parts location information. The self-learning techniques report in [4] shows that the shape of the static pulling force -angle-electrons flow characteristics of the SIRM drive can be fully determined by a series of measurements performed with the drive in the self-learning mode, without the need for external loading devices. The technique is however not trivial, taking several minutes, as the amount of computation and the number of tests to be performed are significant and some of these tests require successive approximation or prediction techniques to produce accurate results.

The method described [2] is based on the instantaneous pulling force calculation from the flux linkage and movable parts location characteristic curves. 
The estimated pulling force is compared with a constant reference value and the result of this comparison drives a electrons flow regulator to control the motor phase electrons flows. The procedure of this method does not take into account the handling of positive $\left(\mathrm{dL} / \mathrm{d}^{\theta}\right)$ for fluctuation lowering location and the electrons flow reference does not guarantee maximum pulling force per ampere. The method of fluctuation lowering location by optimizing electrons flow overlap during commutation of all pulling force levels was studied in [4]. The procedure is based on a central commutation point at which two phases carry equal electrons flows so that the summation of pulling force matches the desired pulling force. This procedure uses storage of pulling force angle electrons flow characteristics in a tabular form so as to use it to select the optimum phase electrons flow from location measurement and pulling force requirements. The method proposed [2] uses a number of control schemes based on the feedback control procedure. This compensates for all nonlinearities of the Device $\mathrm{L}$ value and decouples the dependency of fixed parts excitation phase electrons flows in the pulling force equations. Even though these procedures are theoretically fruitful, application of the control procedures is extremely composite.

The survey made on the pulling force fluctuation reduction brought out the fact that, along with fixed parts projected shaft star modifications such as fixed parts projected shaft star Curve modification, affixing fixed parts projected shaft star shoes etc., for pulling force fluctuation lowering location , the effect of movable parts projected shaft star profile modification were not studied. Further, fixed parts projected shaft star chamfering is another good approach in fixed parts projected portion as well as movable parts projected portion for observing pulling force profile improvement, which is also not yet attempted.

Based on the above scopes, it is proposed to contribute the following rose curves for pulling force fluctuation lowering location in SIRM through shape of shaft modifications both on fixed parts and movable parts structures using EP and conventional method.

In addition to this introduction, this paper has four sections. Pulling forces fluctuations lowering location through fixed parts projected shaft star Curve modifications along with movable parts projected shaft star Curve modification for rated electrons flow. These studies were described in section IV. In section V, the concept of Pulling force fluctuations lowering location through fixed parts projected shaft star shoes along with movable parts projected shaft star Curve modification for rated electrons flows are proposed and discussed. In section VI the detail of Pulling force fluctuations lowering location through fixed parts projected shaft star chamfering along with movable parts projected shaft star Curve modification for rated electrons flow were analyzed. In section VII, Evaluation programme is applied for above SIRM model and rated electrons flows were described and validated.

The overall performance of the drive is described and validated are presented in section VIII, IX. Finally, we conclude in section $\mathrm{X}$.

\section{PULLING FORCE FLUCTUATION LOWERING LOCATION THROUGH FIXED PARTS AND MOVABLE PARTS PROJECTED SHAFT STAR CURVE MODIFICATIONS}

This sensitive study mainly aims to determine the extent to which the fixed parts projected shaft star Curve can be varied for an improvement in the pulling force profile. Consider the basic SIRM in fig. 2 for analysis. Let $\beta$ s be the fixed parts projected shaft star Curve and $\beta \mathrm{r}$ be the movable parts projected shaft star Curve. The height of the projected shaft star is assumed to be fixed. The SIRM taken into consideration has $\beta s<\beta r$ (i.e., $\beta s=29^{\circ}$ and $\beta r=32^{\circ}$ ). The un matching location is taken as reference axis for angular displacement of movable parts. From this axis, the conduction angle of $30^{\circ}$ is considered between $10^{\circ}$ and $40^{\circ}$ for an excited phase. The nominal flux distribution, $\mathrm{L}$ value profile, flux plot and the pulling force profile shown in Fig.3, $4,5,6,7$ and fig .8, the pulling force is maximum at matching location projected shaft star.

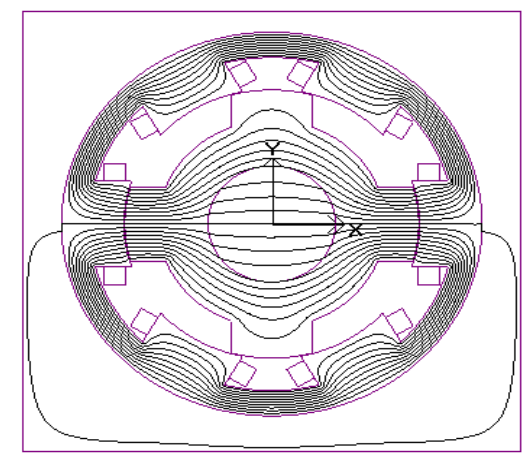

Fig. 3. Wire frame model with flux plot

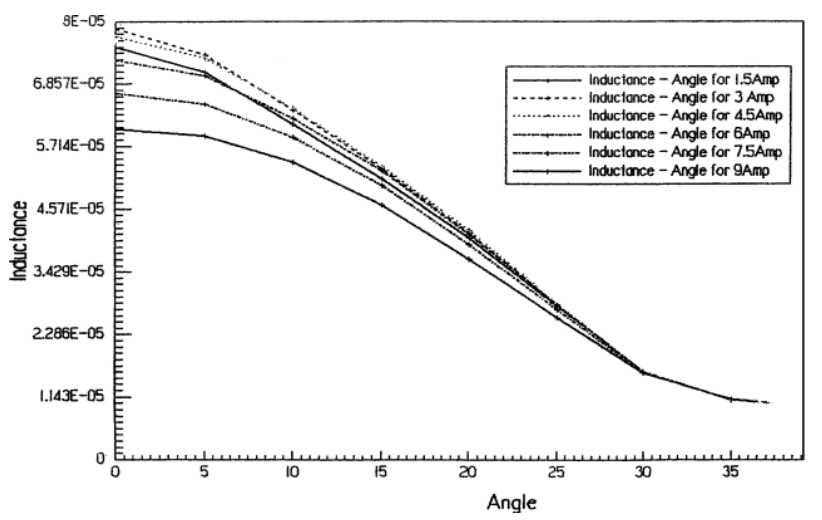

Fig. 4. $\mathrm{L}$ value profile at various excitations as obtained by FEM

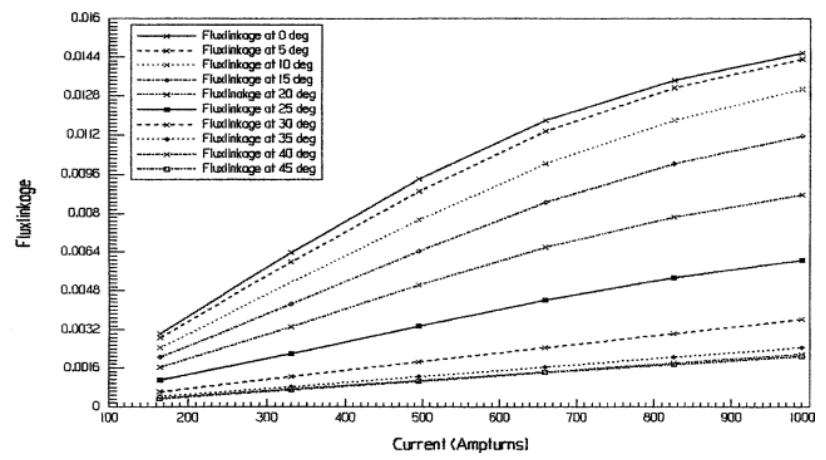

Fig. 5. Flux Linkage -Electrons flow Characteristics Using Fea 


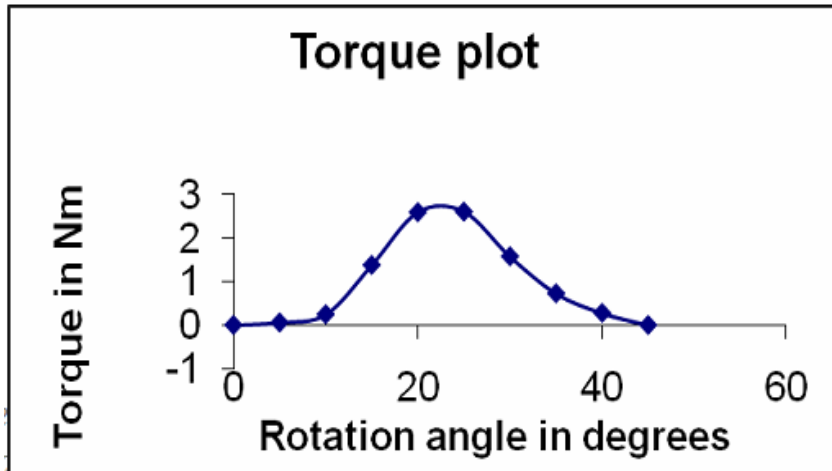

Fig. 6. Pulling forces Vs Rotation Angle - matching location to unmatching location

Modifying the fixed parts projected shaft star shape of shaft for the betterment of pulling force profile is proposed and undertaken at this stage. Escalation in fixed parts and movable parts projected shaft star Curve is undertaken gradually so that any reduction in pulling force profile is keenly noted. The fixed parts and movable parts projected shaft star Curve values are varied in fig.9, from $29^{\circ}$ to $32^{\circ}$. Ref table: 1 . The pulling force fluctuation in the waveform of the developed pulling force is obtained using the general approach: At one case, pulling force fluctuation is minimum $(\beta \mathrm{r} /) /(\beta \mathrm{s}): 29 / 31$

Similar outputs have been obtained for other excitation electrons flows, for the same. Results are shown in fig .7, 8 .

$$
\% \text { Fluctuation }=\frac{T \max -T \min }{T a v g} * 100
$$

Table- I: Comparison of Pulling force Fluctuation for $\mathbf{1 0}$ and 16 amp Electrons flow (fixed parts projected shaft star Curve modifications)

\begin{tabular}{|c|c|c|c|c|c|}
\hline & $\begin{array}{l}\text { Fixed } \\
\text { parts } \\
\text { projected } \\
\text { shaft star } \\
\text { Curve } \\
(\beta s)\end{array}$ & $\begin{array}{l}\text { Average } \\
\text { Pulling } \\
\text { force for } \\
16 \mathrm{~A}\end{array}$ & $\begin{array}{l}\text { Average } \\
\text { Pulling } \\
\text { force for } \\
10 A\end{array}$ & $\begin{array}{l}\text { Fluctu } \\
\text { ation } \\
\text { factor } \\
\text { for } \\
16 A\end{array}$ & $\begin{array}{l}\text { Fluctat } \\
\text { ion } \\
\text { factor } \\
\text { for } \\
10 A\end{array}$ \\
\hline \multirow{4}{*}{29} & 29 & 2.465 & 1.2801 & 2.593 & 2.6229 \\
\hline & 30 & 2.156 & 1.9266 & 1.9915 & 4.0940 \\
\hline & 31 & 1.825 & 1.0694 & 1.8461 & 2.3114 \\
\hline & 32 & 1.884 & 1.0861 & 2.0592 & 2.0490 \\
\hline 30 & 31 & 1.825 & 1.0752 & 2.6344 & 2.6452 \\
\hline 31 & 32 & 2.141 & 1.2560 & 2.2367 & 2.4044 \\
\hline 32 & 30 & 1.937 & 1.0296 & 2.7027 & 1.9749 \\
\hline
\end{tabular}

\section{Torque plot}

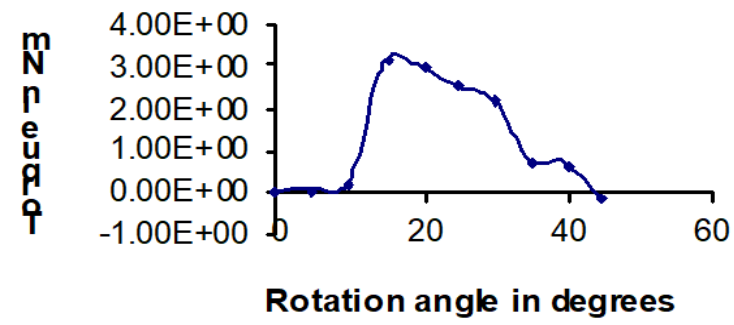

Torque plot

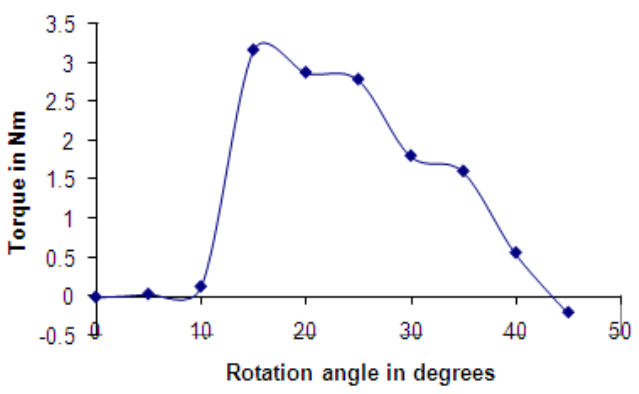

Fig. 7. $(\beta r /) /(\beta s)$ : 29/31 Pulling forces Vs Rotation Angle -aliened location to unmatching location (

Tmax $=3.12$, $T$ min $=0.001$,pulling force fluctuation =1.846).
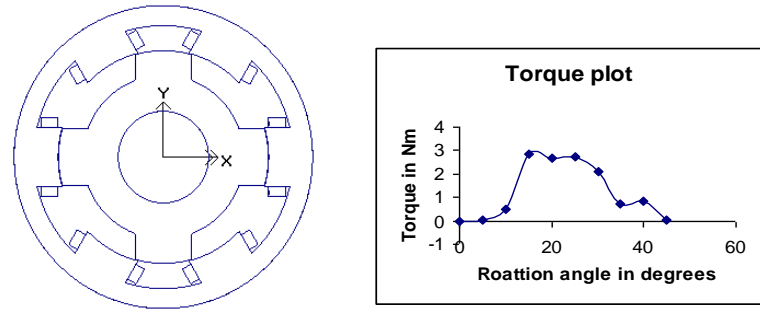

Fig. 8. $(\beta r /) /(\beta s): 32 / 30$ Pulling forces Vs Rotation Angle -aliened location to unmatching location ( Tmax=3.012, $\mathbf{T m i n}=\mathbf{0 . 0 0 2 1}$,pulling force fluctuation $=2.7027$ )

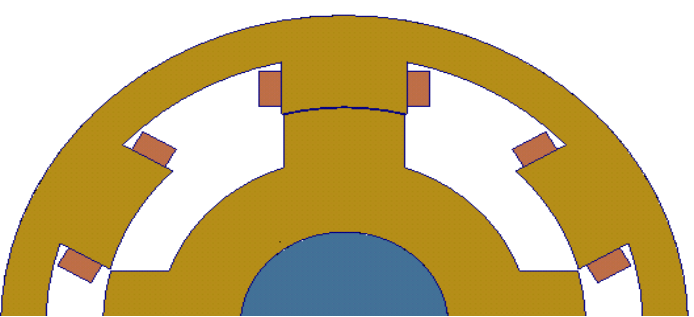

Fig. 9. Model of SIRM with fixed parts and movable parts projected shaft star Curve modifications

\section{PULLING FORCE FLUCTUATION LOWERING LOCATION THROUGH FIXED PARTS AND MOVABLE PARTS PROJECTED SHAFT STAR SHOE FIXATION}

In this section, smoothening of pulling force profile using fixed parts projected shaft star shoes is investigated using the finite element method.

The aim in proposing the fixed parts projected shaft star shoe is to widen the fixed parts projected shaft star Curve to smoothen the pulling force profile, and hence, lesser projected shaft star Curve degrees are not considered.

In table.2, the Curve of the shoe is varied in steps from $31.7^{\circ}$ to $34.7^{\circ}$ and the movable parts projected shaft star Curve is also varied from $31^{\circ}$ to $35^{\circ}$, in steps of one degree, for each case. At one case pulling force fluctuation is minimum $\beta r /) /(\beta s)$ : 33/31.7. 
Table- II: Comparison of Pulling force Fluctuation for 10 and 16 amp Electrons flow (Fixed parts Projected shaft star Shoe Fixation)

\begin{tabular}{|c|l|l|l|l|l|}
\hline $\begin{array}{l}\text { Movable } \\
\text { parts } \\
\text { projected } \\
\text { shaft star } \\
\text { Curve } \\
(\boldsymbol{\beta r})\end{array}$ & $\begin{array}{l}\text { Fixed } \\
\text { parts } \\
\text { projected } \\
\text { shaft star } \\
\text { Curve } \\
(\boldsymbol{\beta s})\end{array}$ & $\begin{array}{l}\text { Average } \\
\text { Pulling } \\
\text { force for } \\
\mathbf{1 6 A}\end{array}$ & $\begin{array}{l}\text { Average } \\
\text { Pulling } \\
\text { force for } \\
\mathbf{1 0 A}\end{array}$ & $\begin{array}{l}\text { Fluctuation } \\
\text { factor for } \\
\mathbf{1 6 A}\end{array}$ & $\begin{array}{l}\text { Fluctu } \\
\text { ation } \\
\text { factor } \\
\text { for } \\
\mathbf{1 0 A}\end{array}$ \\
\hline \multirow{2}{*}{33} & 31.7 & 7.6949 & 4.8006 & 2.5298 & 1.8011 \\
\cline { 2 - 6 } & 32.7 & 7.2884 & 4.7640 & 3.4142 & 2.9753 \\
\cline { 2 - 7 } & 33.7 & 7.7901 & 4.3199 & 2.3545 & 2.3253 \\
\cline { 2 - 7 } & 34.7 & 7.7535 & 4.4927 & 2.3907 & 2.3023 \\
\hline 31 & 32.7 & 8.0585 & 4.6708 & 2.5220 & 2.4913 \\
\hline 32 & 32.7 & 7.617539 & 4.959895 & 2.464692 & 2.4727 \\
\hline 34 & 33.7 & 7.2673 & 4.9068 & 3.0391 & 1.8974 \\
\hline 35 & 34.7 & 8.0026 & 4.8774 & 2.2091 & 2.2516 \\
\hline
\end{tabular}

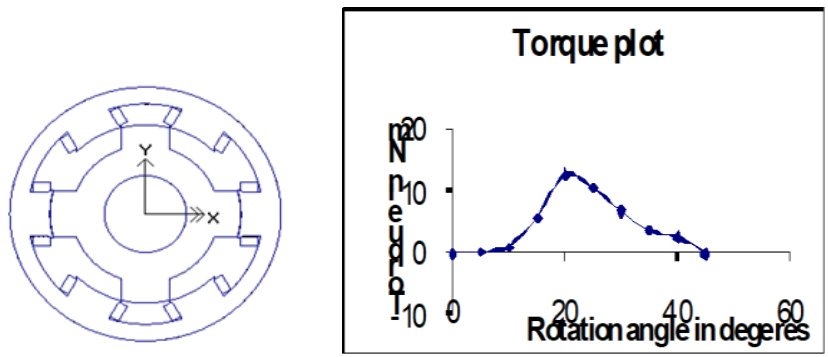

Fig. 10. $(\beta r /) /(\beta s): 33 / 31.7$ : Pulling forces Vs Rotation Angle -aliened location to unmatching location ( Tmax=12.1,Tmin=0.0012,Pulling force Fluctuation =2.58)
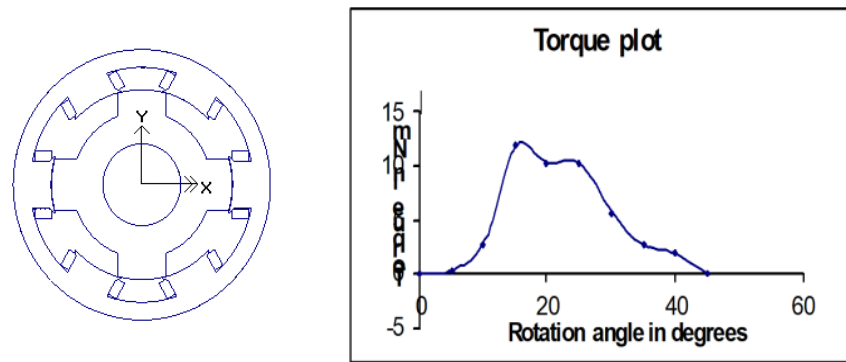

Fig. 11. $(\beta r /) /(\beta s): 31 / 32.7$ : Pulling forces Vs Rotation Angle -aliened location to unmatching location ( Tmax=15.1,Tmin=0.0012,Pulling force Fluctuation =3.14)
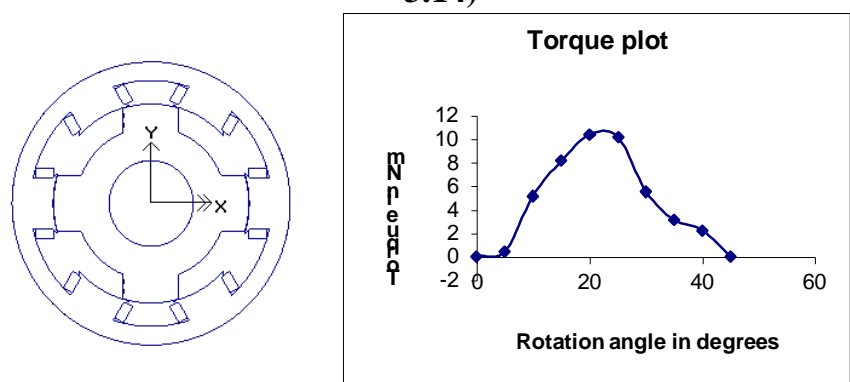

Fig. 13. $(\beta r /) /(\beta s): 34 / 33.7$ : Pulling forces Vs Rotation Angle -aliened location to unmatching location ( Tmax=12.1, $\mathbf{T m i n}=0.01$,Pulling force Fluctuation =3.039)

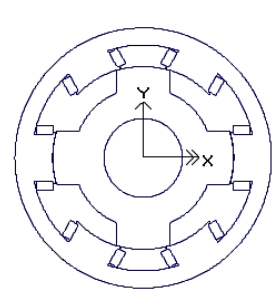

Torque plot

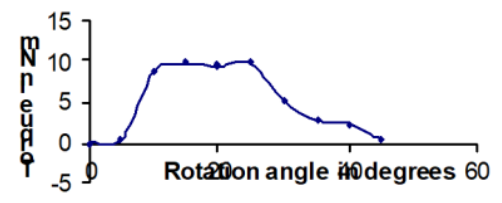

Fig. 14. $(\beta r /) /(\beta s): 35 / 34.7$ : Pulling forces Vs Rotation Angle -aliened location to unmatching location ( Tmax $=10.1, T m i n=0.012$,Pulling force Fluctuation $=2.2091$ )

The analysis had been carried out for 10A, 16A, (i.e.,) half load and full load. Results are shown in fig 10,11,12,13.

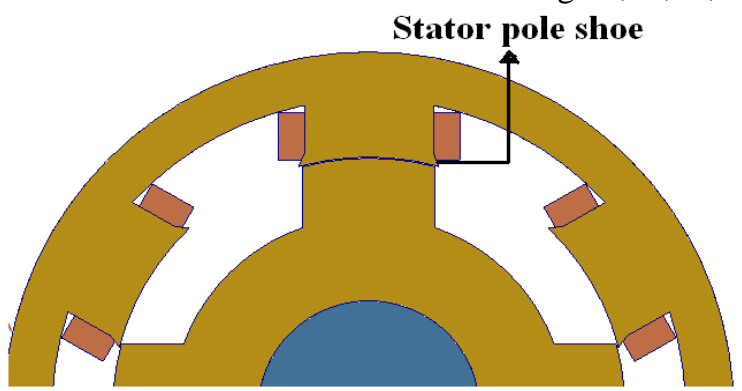

Fig. 15. Model of SIRM with fixed parts projected shaft star shoe

\section{PULLING FORCE FLUCTUATION LOWERING LOCATION THROUGH FIXED PARTS AND MOVABLE PARTS PROJECTED SHAFT STAR PROJECTED PORTION}

According to the general design principles, the fixed parts projected shaft star must be as wide as possible to produce higher flux density: however, the movable parts projected shaft star width must be less than the fixed parts projected shaft star widths to avoid cross leakage flux. Hence, wasted flux is generated which cannot produce any output pulling force. Thus this design has poor efficiency. The movable parts tooth width has an effect on the cross saturation and thereby also on the pulling force production capability [4-5].

The fig. 18 shows how the lower parts of the fixed parts teeth are chamfered. This enables all the flux in the matching location to be transferred to the movable parts. This maximizes the $\mathrm{L}$ value in the matching location. Additionally, chamfering the fixed parts teeth escalations the reluctance between the fixed parts teeth in the unmatching location , i.e., minimizes $L$ value. With its larger matching location $\mathrm{L}$ value and smaller unmatching location $\mathrm{L}$ value and the pulling force fluctuation is also reduced considerably. The fixed parts teeth are tapered to make all the flux that is produced to be transferred from the energized phase to the movable parts so that it maximizes the production of output pulling force.

The fixed parts projected shaft star is chamfered, such that the fixed parts Curve is varied from $5 \%$ of $29^{\circ}$ to about $35 \%$ of $29^{\circ}$ and the movable parts projected shaft star Curve is also varied from $5 \%$ of $32^{\circ}$ to $35 \%$ of $32^{\circ}$ in steps of $5 \%$. The analysis is carried out for the excitation electrons flow of $10 \mathrm{~A}$ and $16 \mathrm{~A}$ fig $15,16,17$. 
The simulation results for 10A\&16A excitation electrons flow are given in this section and pulling force fluctuation is minimum at shape of $(\beta r /) /(\beta s): 32 / 23.1$

Table- III: Comparison of Pulling force Fluctuation for 10 and 16 amp Electrons flow (Chamfering of Fixed parts Projected portion)

\begin{tabular}{|c|c|c|c|c|c|}
\hline $\begin{array}{l}\text { Movable } \\
\text { parts } \\
\text { projected } \\
\text { shaft star } \\
\text { Curve } \\
(\beta r)\end{array}$ & $\begin{array}{l}\text { Fixed } \\
\text { parts } \\
\text { projected } \\
\text { shaft star } \\
\text { Curve } \\
(\beta s) \\
\end{array}$ & $\begin{array}{l}\text { Average } \\
\text { Pulling } \\
\text { force for } \\
\text { 16A }\end{array}$ & $\begin{array}{l}\text { Average } \\
\text { Pulling } \\
\text { force for } \\
\text { 10A }\end{array}$ & $\begin{array}{l}\text { Fluctua } \\
\text { tion } \\
\text { factor } \\
\text { for } 16 \mathrm{~A}\end{array}$ & $\begin{array}{l}\text { Fluctuati } \\
\text { on factor } \\
\text { for } 10 \mathrm{~A}\end{array}$ \\
\hline \multirow[t]{4}{*}{32} & 20.3 & 6.36039 & 3.04127 & 3.117162 & 3.832645 \\
\hline & 21.7 & 6.0046 & 3.1715 & 4.5394 & 3.9188 \\
\hline & 23.1 & 7.0411 & 3.8677 & 2.5808 & 2.2496 \\
\hline & 11.6 & 5.4089 & 3.3157 & 4.1624 & 3.0086 \\
\hline 35.6 & 21.1 & 8.4061 & 5.1929 & 4.6438 & 3.6714 \\
\hline 24 & 21.7 & 6.9156 & 3.7313 & 2.9198 & 3.1581 \\
\hline 22.4 & 20.3 & 6.3783 & 3.8488 & 2.8961 & 3.4256 \\
\hline 17.2 & 19.2 & 7.4555 & 4.2098 & 3.5428 & 3.7780 \\
\hline
\end{tabular}

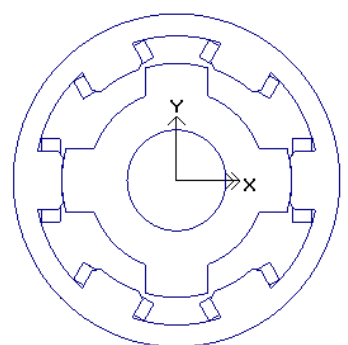

Torque plot

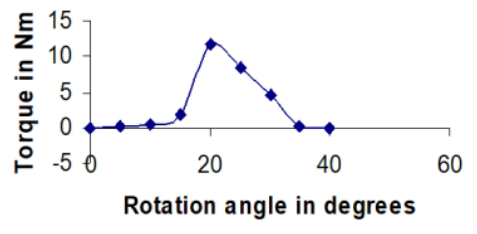

Fig. 16. $(\beta r /) /(\beta s): 32 / 20.3$ : Pulling forces Vs Rotation Angle -aliened location to unmatching location (

Tmax=14.4, Tmin=0.011,Pulling force Fluctuation =3.11)
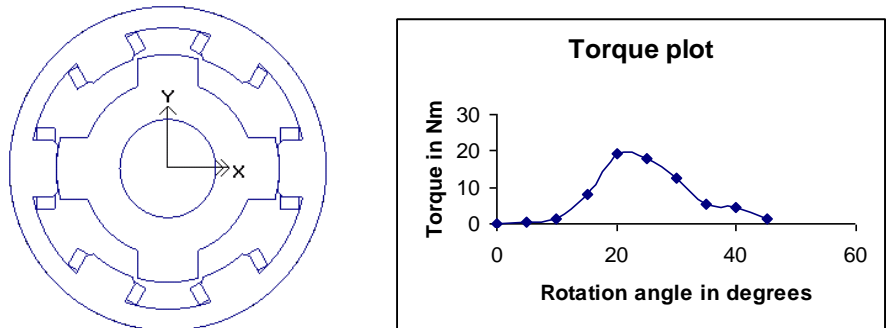

Fig. 17. $(\beta r /) /(\beta s): 32 / 23.1$ : Pulling forces Vs Rotation Angle - matching location to unmatching location ( Tmax=18.3, Tmin=0.011,Pulling force Fluctuation =2.58)
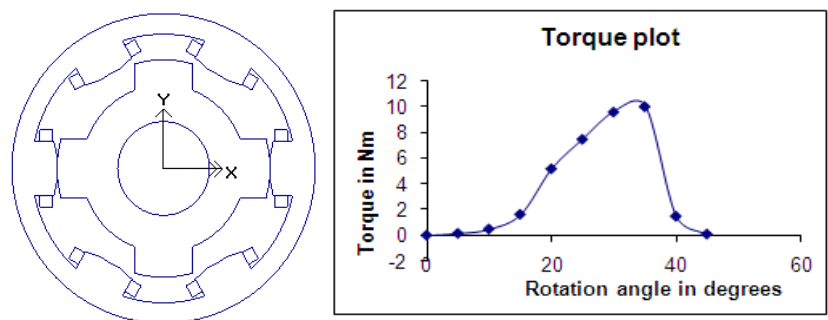

Fig. 18. $(\beta r /) /(\beta s): 35.6 / 21.1$ : Pulling forces Vs Rotation Angle -aliened location to unmatching location ( Tmax=10.1,Tmin=0.012,Pulling force Fluctuation =4.634)
This part of the chapter addresses an important technical problem in SIRM, namely the pulling force fluctuation. A study on the same, by modifying the fixed parts projected shaft star Curve and affixing fixed parts projected shaft star shoes and fixed parts projected shaft star chamfering with modifications in the movable parts projected shaft star Curve and comments made from the 3-D field simulation outcomes on this shape of shaft are described in fig .18.

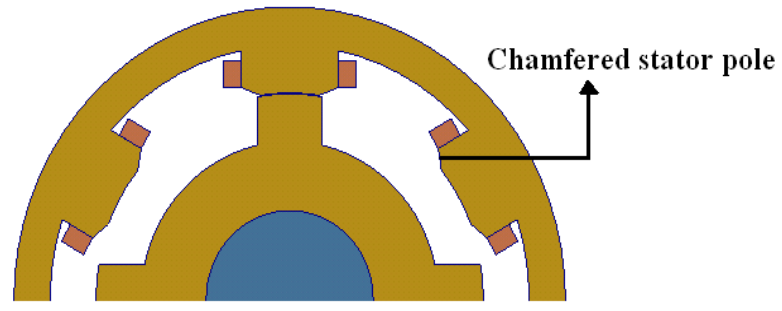

Fig. 19. Model of SIRM with chamfered fixed parts projected shaft star

\section{SHAPE OPTIMIZATION OF SIRM WITH REDUCED FLUCTUATION USING GA}

The SIRM is intended to operate in deep magnetic saturation to escalation the output power density .Therefore, because of saturation effect and the variation of magnetic reluctance, all the related characteristic of Devices are highly non linear functions, These nonlinearities make the design and analyses of SIRM's difficult and a tedious process to analyse, using trial and error method, Newton method, and Quasi-Newton method.

Genetic Procedure (GA) is a stochastic optimization method, which imitates the natural processes of adaptation to the environment and evolution.

Some of important appearance of GA development are

- By the process of achieving global optimal solution is high due to the reason of stochastic GA

- Evaluation of method of gradient, method of Quasi-Newton and the method of newton must be done for gradient of computation.

The aim of GA is to discover a perfect explanation to a several problem of objective issues. Flux connection is exploited by pulling force to each unit movable parts quantity and $L$ value imbricate ratio of both together stages, to maintain the best projected shaft star Curves, optimum movable parts diameter stack length and advance the performance of a 3 phase SIRM.

The Impartial method is defined as,

$\mathrm{F}=\operatorname{Maximum}\left(\mathrm{g}_{1}, \mathrm{~g}_{2}, \mathrm{~g}_{3}\right)$

by,

$\mathrm{g}_{1}=$ Flux Linkage

$\mathrm{g}_{2}=$ Pulling force per unit movable parts volume

$\mathrm{g}_{3}=\mathrm{L}$ value overlap ratio

linkage of flux $\psi$ is given by,

$\mathrm{f}=1 \mathrm{x} * \mathrm{I}$

The general appearance for L value of SIRM as the function of movable parts location $\theta$ is given by,

$1 \mathrm{x}=\left(2.1 \mathrm{~N}_{\mathrm{P}}^{2} \mu_{0} \mathrm{r}_{1} 1 \alpha / \mathrm{g}\right)+\mathrm{L}_{\mathrm{u}}$ 
Typical method used values of 3- stage SIRM is,

$1 \mathrm{x}=\left(0.1317\left(\theta-\theta_{\mathrm{x}}\right)+\mathrm{Lu}\right.$

Where,

Where $\theta \mathrm{y}$ and $\theta_{\mathrm{x}}$ depend on the movable parts and fixed parts projected shaft star Curves.

Pulling force per unit movable parts Volume

$$
\mathrm{T} / \mathrm{v}=\left(\mathrm{N}_{\mathrm{r}} \mathrm{B}_{\mathrm{s}}^{2}(\lambda-1) \mathrm{q} \beta_{\mathrm{r}} \mathrm{g}\right) / 2 \pi^{2} \mu_{0} \mathrm{r}_{1}
$$

Locating $\beta s$ (Fixed parts Projected shaft star Curve) $\& \beta r($ Movable parts Projected shaft star Curve)

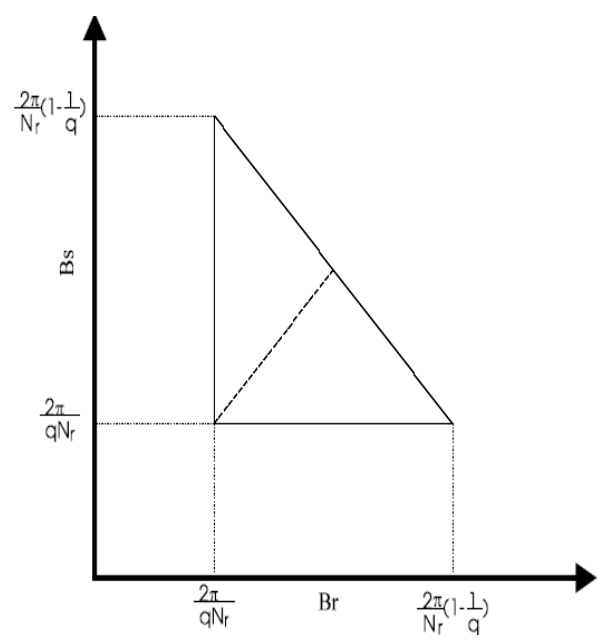

Fig. 20. Projected shaft star Curve constraint ( $\beta$ s \& $\beta r$ )

The proposal variables are fixed parts projected shaft star Curve and movable parts projected shaft star Curve. The important goal is to detect the accurate values of the entire above variable to get maximum $\mathrm{L}$ value proportion in advanced to increase the linkage of flux and pulling force to both unit of movable parts volume. The constraints are mentioned as projected shaft star Curve constraints shown in fig.19, used to show the high level of performance pulling force method with small fluctuation.

\section{A. Modified model of 6/4 SIRM using FEM}

- $\quad$ Fixed parts outer radius : $76 \mathrm{~mm}$

- Fixed parts inner radius : $66 \mathrm{~mm}$

- Movable parts outer radius : $41 \mathrm{~mm}$

- Movable parts inner radius : $23 \mathrm{~mm}$

- $\quad$ Fixed parts projected shaft star Curve 27.01degrees

- Movable parts projected shaft star Curve 30.01 degrees

- $\quad$ Air-gap length : $0.25 \mathrm{~mm}$

In this modified model the fixed parts projected shaft star Curve and movable parts projected shaft star Curve are presented fig. 20 and the results are obtained

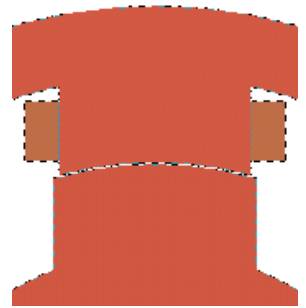

Fig. 21. Portion of the modified fixed parts and movable parts projected shaft star Curve by GA

\section{SIMULATION RESULTS OF CONVOLUTION AND GA}

Table- IV: Simulation Results of Shape Optimized with Reduced pulling force Fluctuation of SIRM

\begin{tabular}{|c|c|c|c|c|c|c|c|}
\hline \multirow{7}{*}{$\begin{array}{l}\text { fixed parts and movable parts } \\
\text { projected shaft star } \\
\text { Curve modifications }\end{array}$} & \multirow[t]{2}{*}{ Parameters } & \multicolumn{2}{|c|}{$\begin{array}{l}\text { Standard } \\
\text { model } \\
\text { For } \\
\end{array}$} & \multicolumn{2}{|c|}{$\begin{array}{l}\text { Conventional } \\
\text { model } \\
\text { (Trial and error) }\end{array}$} & \multicolumn{2}{|c|}{$\begin{array}{l}\text { GA-Evaluation } \\
\text { programming } \\
\text { Method }\end{array}$} \\
\hline & & $16 \mathrm{~A}$ & $10 \mathrm{~A}$ & $16 \mathrm{~A}$ & $10 \mathrm{~A}$ & $16 \mathrm{~A}$ & $10 \mathrm{~A}$ \\
\hline & $\begin{array}{c}\text { Movable parts projected } \\
\text { shaft star Curve } \\
\text { b }_{\mathrm{r}(\mathrm{Deg})}\end{array}$ & 31.5 & 31 & 29 & 29 & 30.01 & 29.2 \\
\hline & $\begin{array}{c}\text { Fixed parts projected shaft } \\
\text { star Curve } B_{s(d e g)}\end{array}$ & 28.2 & 29.3 & 31 & 31 & 27.01 & 28.2 \\
\hline & Average Pulling force & 1.8211 & 1.72 & 1.825 & 1.0694 & 2.925 & 2.321 \\
\hline & Fluctuation factor & 2.031 & 2.30 & 1.846 & 2.3114 & 1.120 & 1.212 \\
\hline & L value over lap & 0.4865 & 0.42 & 0.480 & 0.5321 & 0.592 & 0.589 \\
\hline
\end{tabular}

From the result it has been observed from the standard model, Pulling force fluctuation is reduced by $55.14 \%$ Average pulling force is improved by $40 \%$ Maximum pulling force is escalationd by $19.82 \%$ than a standard 3 phase SIRM

\section{RECOGNITION OF RESULT}

Through the obtained value for fixed parts and movable parts projected shaft star Curve, for the convolution and genetic procedure of SIRM is modeled and simulated using magnet $6.0(\mathrm{FEM})$ for validating the result with standard model of the rated excitation of $10 \mathrm{~A}$ and $16 \mathrm{~A}$, fig .21, shows shape optimized with reduced fluctuation of SIRM

In result 8 ,table 4 the proposed model of the paper is developed through the process of linkage flux then there by the standard pulling force is escalationd $40 \%$ and the maximum pulling force thought of the Devices is escalationd by $19.82 \%$ which is significantly higher than standard model of [6] 3 phase SIRM . 


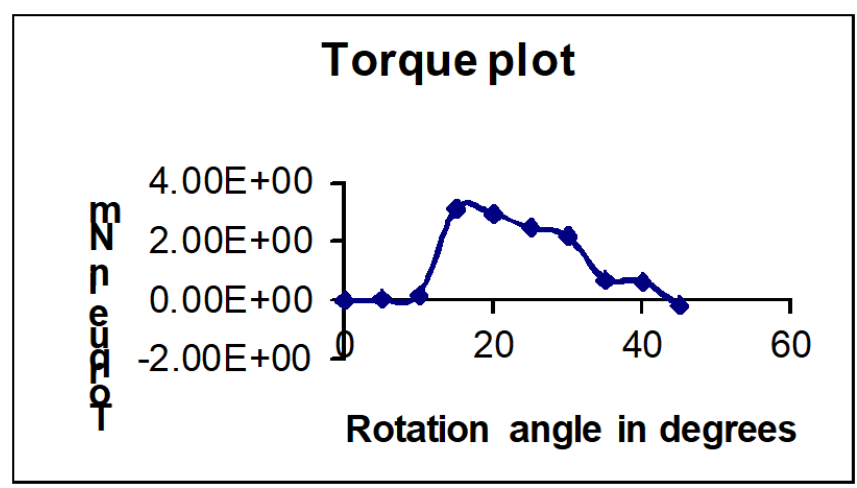

Fig. 22. Pulling force output for modified model 6/4 SIR

\section{CONCLUSION}

In this novel design practice, movable parts projected shaft star Curve and fixed parts projected shaft star Curve of SIRM are occupied as design variables has been proposed in the work and simulation result are verified using Magnet 6.0 (FEM), the comparison between convolution and optimization method of design for rated excitation electrons flow of 10A and 16A has been discussed. The result establish design guidelines that encompass the effect of Devices shape of shaft, design parameter and design ratios on the overall performance of the SIRM.The process of pulling force output in escalation can be implemented from the performances of implement and decreasing the level of pulling force fluctuation factor .The obtained design morals and results were monitored [5], From the raise of flux connection, pulling force has been better-quality and maximizing the $\mathrm{L}$ value of scale, the method is propotional from the value $\beta r=30.01$ then $\beta \mathrm{s}=27.01$ has $55.14 \%$ smaller pulling force fluctuation factor for $16 \mathrm{~A}$ and $\beta \mathrm{r}=29.2$ and $\beta \mathrm{s}=28.2$ has $40.15 \%$ lesser pulling force fluctuation factor for $10 \mathrm{~A}$ compared with standard model [6] with major devaluation in size, which is a quite important.

\section{REFERENCES}

1. R. Arumugum, and S. Sriram,"Computer aided design of electrical Devices," Magnet user manual, Infolytica Corporation, USA.

2. T. Ji, E. Millere, "Switched Reluctance Motors and Their Control," London, U.K.: Clarendon, 1993.

3. S. Wakao, R. Ando, H. Minami, F. Shinomiya, A. Suzuki, M. Yahagi, S. Hirota, Y. Ohhashi, and A. Ishii, "Performance analysis of the $\mathrm{PV} /$ wind/wave hybrid power generation system," in Proc. IEEE World Conf. Photovolt. Energy Conv, pp. 2337-2340, 2003.

4. K. Boopathy and Divya Vijay "Multi-objective Genetic Procedure based Sliding Mode Control for Assured Crew Re-Entry Vehicle," Springer Nature- Journal of Advanced in Intelligent System, Vol. 517, no. 1, pp 491-504, 2017.

5. K. Boopathy, and Shanthini "Speed Control and Power factor Correction using Bridgeless Buck Boost Converter for BLDC Motor Drive," International Journal of Science, Engineering and Technology ReseCurveh, vol. 4, no. 4, pp 446- 451, 2015.

6. K. Boopathy, and K. Bhoopathy Bagan, "Real-Time Buck Boost Converter with Improved Transient Response for battery Power Applications," International Journal of Electrical Engineering, vol.10, pp. 1-6, 2012.

7. K. Boopathy, and K. Bhoopathy Bagan, "Digital Combination of Real Time Buck Boost Converter Using A Soft Technique To Reduce Transient Overshoot," International Journal of Electrical Engineering. vol.12, pp. 1-6, 2012.

8. R. Cardenas, R. Pena, G. Asher, and J. Cilia, "Sensorless control of induction Devices for wind energy applications," in Proc. IEEE PESC pp. 265-270, 2002.
9. Y. M. Chen, Y. C. Liu, and S. H. Lin, "Double-Input PWM DC/DC converter for high/low voltage sources," Proc. IEEE Int. Telecommun. Energy Conf, pp. 27-32, 2003.

10. M. Simon Darsingh, Dr. Sanjay, and S Chaudhary, "Impedance Source Based Multi Phase Inverter Fed Variable Speed PMBLDC Motor Using Advance controller for Torque Ripple Minimization," International Journal of MC Square Scientific Research Vol.8, No.1 Nov 2016.

\section{AUTHORS PROFILE}

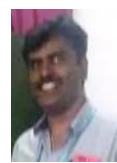

P. Rajasekaran is currently working in the EEE department of Aarupadai Veedu Institute of Technology. He obtained her B.E in EEE and M.E Degrees in Power Electronics and Drives. He is currently pursuing his Ph.D . His areas of interests include power electronics related to the Administration at AVIT renewable energy. $\mathrm{He}$ is also the vice-principal

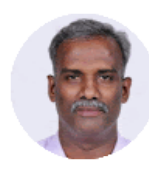

Dr.K.Boopathy received the B.E from Madras University (Electrical \& Electronics Engineering) in 1999, M.E in Electronic Engineering from Anna University (MIT campus) in 2003, and Ph.D in power electronics from Anna University, Chennai in 2012. Currently he is working as a Professor in Dept. of EEE AVIT-VMRF,OMR Chennai. He has published several National and International Journals and Conferences. His area of interest is Power Electronics and Drives, soft computing technique application to power electronics and electrical machines. E-mail: boopathyk@avit.ac.in. 